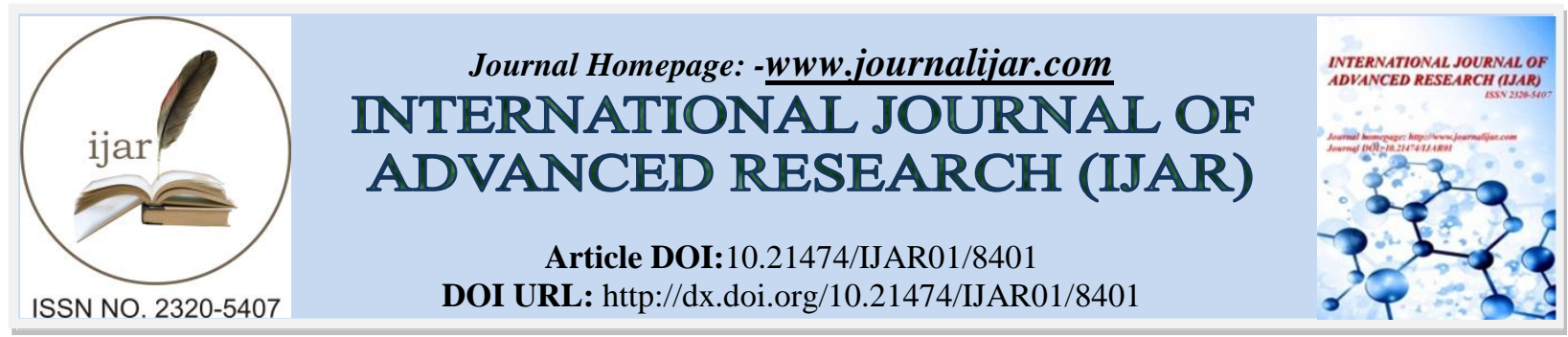

RESEARCH ARTICLE

\title{
LIFESTYLE DETERMINANTS:AN OVERVIEW.
}

Muzamil Hassan ${ }^{1}$, Sabira Aalia Dkhar ${ }^{2}$ and Ambrine Ashraf ${ }^{1}$.

1. Demonstrator, Department of Community Medicine, Government Medical College, Srinagar.

2. Medical Officer, Department of Community Medicine, Government Medical College, Srinagar.

\section{Manuscript Info}

Manuscript History

Received: 12 November 2018

Final Accepted: 14 December 2018

Published: January 2019

Key words:-

lifestyle,healthy,wellbeing,determinants.

\begin{abstract}
Background: Lifestyle of an individual is the main contributor of a person's health and well-being.Method: A number of articles were reviewed to get an overview about the various determinants of health and how they impact our lives.Results; every activity of an individual from dawn to dusk has an important contribution in framing the physical and mental dimension of a person. A healthy balance needs to be maintained to ensure physical, mental and social wellbeing of an individual.
\end{abstract}

Copy Right, IJAR, 2017,. All rights reserved.

\section{Introduction:-}

Lifestyle includes the day to day behaviours and functions of individuals in job, activities, fun and diet.(1). The term was introduced by Austrian psychologist Alfred Adler with the meaning of "a person's basic character as established early in childhood".(2).In todays world Non-Communicable diseases have creeped up as the most common cause of mortality and morbidity, unhealthy lifestyle being the contributor of this modern time epidemic. According to WHO, $60 \%$ of related factors to individual health and quality of life are correlated to lifestyle. Variables of lifestyle that influence the health of an individual can be categorized as (a) Diet and Body Mass Index (b) Exercise (c) Sleep (d) Sexual behavior (e) Substance use disorder (f) Medication abuse (g) Application of modern technologies (h) Recreation and (i) Study (1). Most important is to maintain the balance between various variables to achieve an optimum level of health. A review of various articles was done to get an overview about the variables that have a bearing on the wellbeing of an individual.

\section{Effect of dietary patterns:-}

A study was done by P.K.Newby et al to see the effect of dietary patterns on BMI and waist circumference in adults. They concluded that consuming a diet high in fruits, vegetables, reduced fat, dairy, and whole grains and low in red and processed meat, fastfood, and soda was associated with smaller gains in BMI and waist circumference.(4) KE Foster-Schubert et al conducted a year-long study, 4-arm randomized trial among 439 overweight-to-obese postmenopausal sedentary women in order to determine the effects of a low calorie, low-fat diet (D), a moderateintensity, facility-based aerobic exercise program (E), or the combination of both interventions (D+E), vs. a nolifestyle change control (C) on change in body weight and composition. At the end of the trial they found that a year-long lifestyle change programme, integrating either combined or separate dietary weight loss or moderate-tovigorous aerobic exercise interventions,produced clinically important and significant reductions in body weight and improvements in body composition among overweight-to-obese postmenopausal women.Krishnan Bhaskaran et al conducted a population based Cohort study to find out the association between BMI and risk for 22-specific cancers. They included 5.24 million subjects in their study and 166955 developed cancer of interest. Out of the 22 cancers BMI was associated with 17 cancers although the effects varied with site.(6)

Corresponding Author:-Muzamil Hassan.

Address:-Demonstrator, Department of Community Medicine, Government Medical College, 


\section{Effect of physical activity:-}

Physical activity promotes normal growth and development and physical inactivity is a modifiable risk factor for various lifestyle diseases including diabetes mellitus, hypertension, cardiovascular diseases etc. According to a review done by Darren.E.R physical activity on regular basis contributes to the primary and secondary prevention of various chronic diseases and reduces the risk of premature death. According to the study there is a linear relationship between the volume of physical activity and health status, in a way that the most physically active people are at the lowest risk. However, the improvements in health status are seen when people who are found to be least fit become physically active. (7)

\section{Effect of sleep:-}

Sleep being a biologic process is essential for life and optimal health. According to a literature review conducted by Goran Medic and others numerous factors contribute to disrupted sleep including lifestyle and environmental factors which include psychosocial and iatrogenic effects. Sleep is vital to the optimum functioning of the body. According to the review sleep disruption leads to a number of short-term and long-term effects. Some of the short term consequences include heightened stress response, pain depression, anxiety etc. In case of adolescents and children sleep disturbance leads to poor school performance and behavioural problems. Long term consequences include hypertension, dyslipidemia CVD, weight gain etc. The physiologicic consequences of disrupted sleep are as damaging as those of short sleep duration. (8)

\section{Effect of sexual behavior:-}

According to a study by Simone Gonclaves de Assis and others on the adolescent sexual behavior and risk factors to health, more of the risk factors like suicidal thoughts, less frequent codom use, more cannabis use were found in adolescents with homosexual/bisexual behavior compared to those with heterosexual behavior. Adolescents with homosexual/bisexual behavior talked more about their positive personal and negative relationship experiences than their heterosexual peers and talked less about religion.(9) In a study by Sonya $S$ and others to find out the social and emotional consequences of refraining from sexual activity among sexually experienced and inexperienced youths in California reported that the percentage of adolescents who reported only positive consequences (felt responsible, friends were proud) dramatically decreased overtime whereas the percentage that reported negative consequences (felt left out,partners became angry) increased steadily.(10) In a study by Hui Liu and others on partnered sexuality and cardiovascular risk among older men and women reported that the cardiovascular risk was lower among the people who were sexually active especially in men.The sexually active men had lower levels of CRP five years later than sexually inactive men.They also suggested that while infrequent sex has some health benefits having sex too frequently may be detrimental especially for older men.(11)

\section{Effect of substance use:-}

Substance use disorders are featured by repeated use of either alcohol,drugs or both leading to problems like inability to control use of the substance,failing to meet the requirements at work, home or school,deterioration of health and waste of time in getting,using or recovering from the after effects of using the substance. According to a report by Rachel N Lipari parent substance use disorders (SUDs) can have negative impacts on children, including lower socioeconomic status and more difficulties in academic and social settings and family functioning when compared with children living with parents without an SUD.(12) In a study conducted by Laura Landers and others on the impact of substance use disorders on families and children has reported that the effects of substance use disorders (SUD) are felt by the whole family. SUDs negatively affect emotional and behavioural patterns from the inception of the family, resulting in poor outcomes for the children as well as adults. (13)

\section{Effect of medication use:-}

Medication misuse means taking medicines in a manner or dose other than prescribed,using someone else's prescription or taking a medicine to feel euphoria.(14) Prescription drug use is seen especially among elderly as they are more likely to be taking prescription medications. Drug misuse and abuse in elderly is of special concern because it can cause cognitive and physical impairment increasing their risk for falls, motor vehicle accidents etc. (15). Prescription stimulants are used to treat attention deficit hyperactivity disorder (ADHD). According to study by Shaheen and others with prescription stimulants in individuals with and without attention deficit hyperactivity disorder, although stimulants improve an individual's performance when given a rote-learning task,they do not offer as much help to people with greater intellectual abilities. Stimulants do not increase IQ. Stimulants are more effective at correcting deficits than enhancing performance. Harmful effects of stimulants may include sudden death. (16) 


\section{Effect of advancement in technologies:-}

Advances in technologies has made life easier for man but they have brought along ill-effects in their wake.According to a review by Elizabeth $\mathrm{M}$ Joseph and others information and communication technologies (ICTs) have helped to improve health promotion interventions. (17). According to Whileand Dewsbury, the US National Broadband Plan identified a key role for ICTs in improving health and healthcare through enhancing care, delivery, coordination and engagement with patients. (18) The use of ICTs in disease treatment, preventive vaccination, medical appointments, and medication for long-term self-management has had a positive influence on healthcare delivery. (19). However the use of ICTs without any check can make the people adopt sedentary lifestyles. (20)(21).

\section{Effect of recreational activities:-}

In a study William K Goodman and others have reported that leisure activities levy various health benefits by increasing individuals' perception of utilizing the time efficiently. Recreational activities have depression ameliorating effects. (22) According to an article by Geoffery Godbey being outside in natural surroundings improves health. Children's health problem can be mitigated by outdoor play, sports and nature study. (23).

\section{Effect of education:-}

1. In a study Hamad $\mathrm{R}$ and others have reported that educational attainment has an effect on the majority of health outcomes mostly beneficial, some negative in his systematic review, while the meta-analysis done by him demonstrated small beneficial effects for mortality, smoking, and obesity. (24) According to a study by Emily B. Zimmerman and others in understanding the relationship between education and health, education is critical to social and economic development and has an extreme effect on population health. (25)

2. Robert A.Hahn and Benedict I.Truman in their study have reported that basic educational expertise and skills, like fundamental knowledge, reasoning, emotional self-regulation and intractional abilities are the critical components of the health and that education is a basic social determinant of health. (26) According to study by Baker et al neurological development of higher-order cognitive skills occurs at least through late adolescence and is highly responsive to environmental stimulation.(27) Physical and chemical features of environment as well as the social and economic relations have important effects on an individual. Education in various forms influences these environments and social interactions, changing the nature of the milieu people inhabit and also increase the strength of individuals and other agencies to protect themselves against potential upset to health. (28)

\section{Conclusion:-}

Our aim was to get an overview about the various determinants of the lifestyle and how they impact the health of an individual. Findings after reviewing the literature indicate that each and every activity of an individual has a bearing on the health of the person and a balance has to be maintained so that the people are able to face newer challenges in life. Healthy lifestyle is the best strategy to reduce the burden of mortality and morbidity on the healthcare system.

\section{References:-}

1. Dariush D Farhud.Impact of lifestyle on Health. Iran J Public Health, Vol. 44, No.11, Nov 2015, pp.1442-1444.

2. Ziglio E, Currie C, Rasmussen VB. (2004). The WHO cross-national study of health behavior in school aged children from 35 countries: findings from 2001-2002. J School Health, 74(6): 204-206.

3. PK Newby, Denis Muller, Judith Hallfrisch, Ning Qiao, Reubin Andres, and Katherine L Tucker. Dietary patterns and changes in body mass index and waist circumference in adults1-3. Am J Clin Nutr 2003; 77:14171425. Printed in USA. () 2003 American Society for Clinical Nutrition.

4. KE Foster-Schubert1,2, CM Alfano3, CR Duggan1, L Xiao1, KL Campbell4, AKong1, C Bain1,CY Wang1,2, G Blackburn5, and A McTiernan1,2. Effect of diet and exercise, alone or combined, on weight and body composition in overweight-to-obese post-menopausal women. Obesity (Silver Spring). 2012 August; 20(8): 1628-1638. doi:10.1038/oby.2011.76.

5. Krishnan Bhaskaran, Ian Douglas, Harriet Forbes, Isabel dos-Santos-Silva, David A Leon, Liam Smeeth. Body-mass index and risk of 22 specifi c cancers: a population- based cohort study of $5 \cdot 24$ million UK adults.

6. Darren E.R. Warburton, Crystal Whitney Nicol, Shannon S.D. Bredin. Health benefits of physical activity: the evidence. CMAJ 2006; 174(6):801-9.

7. Goran Medic1, 2 Micheline Wille1 Michiel EH Hemels1. Short- and long-term health consequences of sleep disruption.Nature and Science of Sleep.19 May 2017.

8. Simone Gonçalves de AssisI Romeu GomesII Thiago de Oliveira PiresIII. Adolescence, 
9. Sexual behavior and risk factors to health. Rev Saúde Pública 2014; 48(1):43-51.

10. Sonya S. Brady, PhD, and Bonnie L. Halpern-Felsher, PhD. Social and Emotional Consequences of Refraining From Sexual Activity among Sexually Experienced and Inexperienced Youths in California. American Journal of Public Health | January 2008 Vol 98, No. 1

11. Hui Liu, Department of Sociology, Michigan State University Linda Waite, Department of Sociology \& NORC, University of Chicago Shannon Shen, and Department of Sociology, Michigan State University Donna Wang Department of Medicine, Michigan State University. Is Sex Good for Your Health? A National Study on Partnered Sexuality and Cardiovascular Risk among Older Men and Women. J Health Soc Behav. 2016 September; 57(3): 276-296.

12. Rachel N. Lipari, Ph.D., and Struther L. Van Horn, M.A. Children Living With Parents Who Have a Substance Use Disorder. https://www.samhsa.gov/data/sites/default/files/report_3223/ShortReport-3223.html.

13. Laura Lander, Janie Howsare and Marilyn Byrne.The Impact of Substance Use Disorders Families and Children: From Theory to Practice. Soc Work Public Health.2013; 28 (0): 194-205.

14. Misuse of Prescription Drugs. National Institute on Drug Abuse (NIDA). Last Updated December 2018 https://www.drugabuse.gov.

15. Belinda Basca. The Elderly and Prescription Drug Misuse and Abuse. Prevention-Tactics- Vol 09- No02-2008.

16. Shaheen E. Lakhan \& Annette Kirchgessner. Prescription stimulants in individuals with and without attention deficit hyperactivity disorder: misuse, cognitive impact, and adverse effects. Global Neuroscience Initiative Foundation, Los Angeles, California.

17. Elizabeth M Joseph-Shehu, 1, 2 Busisiwe P Ncama1. Evidence on health-promoting lifestyle practices and information andcommunication technologies: scoping review protocol. BMJ Ope 2017; 7:e014358.

18. While A, Dewsbury G. Nursing and information and communication technology (ICT): a discussion of trends and future directions.Int J Nurs Stud 2011; 48:1302-10.

19. Cocosila M, Archer N. Adoption of mobile ICT for health promotion: an empirical investigation. Electronic Markets 2010; 20:241-50.

20. Pirincci E, Rahman S, Durmuş A, et al. Factors affecting health-promoting behaviours in academic staff. Public health $2008 ; 122: 1261-3$.

21. Turkmen M, Ozkan A, Murat K, et al. Investigation of the relationship between physical activity level and healthy life-style behaviors of academic staff. Educ Res Rev 2015; 10:577-81.

22. William K Goodman, Ashley M Geiger, and Jutta M Wolf. Leisure activities are linked to mental health benefits by providing time structure: comparing employed, unemployed and homemakers. J Epidemiol Community Health. 2017 January; 71(1): 4-11.

23. Geoffrey Godbey. Outdoor Recreation, Health, and Wellness: Understanding and Enhancing the Relationship. May 2009 v RFF DP 09-21. http://www.rff.org/files/sharepoint/.

24. Hamad R, Elser H, Tran DC, Rehkopf DH, Goodman SN. How and why studies disagree about the effects of education on health: A systematic review and meta-analysis of studies of compulsory schooling laws. Soc Sci Med. 2018 Sep; 212:168-178.

25. By Emily B. Zimmerman, Steven H. Woolf, and Amber Haley. Understanding the Relationship Between Education and Health. Population Health: Behavioral and Social Science Insights. https://www.ahrq.gov/professionals/education/curriculum-tools/population-health/zimmerman.html.

26. Robert A. Hahn and Benedict I. Truman. Education Improves Public Health and Promotes Health Equity. RoInt J Health Serv. 2015; 45(4): 657-678. doi:10.1177/0020731415585986.

27. David P. Baker, Juan Leon, Emily G. Smith Greenaway, John Collins, and Marcela Movit. The Education Effect on Population Health: A Reassessment. Popul Dev Rev. 2011 June; 37(2): 307-332.

28. Leon Feinstein, Ricardo Sabates, Tashweka M. Anderson, Annik Sorhaindo and Cathie Hammond* What are the effects of education on health? Measuring the Effects of Education on Health And Civic Engagement: Proceedings Of The Copenhagen Symposium - (c) Oecd 2006. 